\title{
Characterisation of Drug-Related Problems and Associated Factors at a Clinical Pharmacist Service-Naïve Hospital in Northern Sweden
}

\author{
Cecilia Peterson $^{1} \cdot$ Maria Gustafsson $^{1}$
}

Published online: 19 May 2017

(c) The Author(s) 2017. This article is an open access publication

\begin{abstract}
Background Polypharmacy and increased sensitivity to side effects cause adverse drug events, drug-drug interactions and medication errors in the elderly.

Objective The objective of this study was to investigate the prevalence and type of drug-related problems and associated factors among patients admitted to a clinical pharmacist service-naïve medical ward in an inland hospital in northern Sweden.

Methods During September-November 2015 and February-April 2016, clinical pharmacists working as part of a ward team on the medical ward conducted 103 medication reviews. Drug-related problems were identified and classified. Associated factors, drug classes and specific drugs involved were also investigated.

Results The clinical pharmacists identified 133 drug-related problems in 66\% [68/103] of the study population. The most common drug-related problems in this study were inappropriate drug use and interactions. Cardiovascular drugs and psychotropic drugs were most commonly involved. Drug-related problems were more frequently observed at higher age, increasing number of drugs prescribed and in patients with reduced renal function. In the multivariate analysis, only the number of prescribed drugs was still significant.

Conclusion Drug-related problems were commonly observed among patients admitted to the medical ward. Medication reviews conducted by clinical pharmacists as
\end{abstract}

Maria Gustafsson

maria.gustafsson@umu.se

1 Department of Pharmacology and Clinical Neuroscience, Division of Clinical Pharmacology, Umeå University, 90187 Umeå, Sweden part of a ward team resulted in several interventions to improve the patients' drug treatment.

\section{Key Points}

Drug-related problems such as inappropriate drug use and drug-drug interactions are commonly occurring among old people admitted to medical wards.

Involving clinical pharmacists in the ward team may reduce drug-related problems and improve quality of drug therapy.

\section{Introduction}

The most common intervention after visiting the primary healthcare system is the prescription of drugs, and approximately two-thirds of these visits result in at least one prescription [1]. The proportion of patients treated with drugs increases with age. In Sweden, individuals over 75 years old represent more than $25 \%$ of total drug consumption, although they constitute only $9 \%$ of the population [1]. This is of concern because the sensitivity to side effects of drugs also increases with age, as a result of decreased renal function, cognitive function and body composition [2]. In addition, polypharmacy increases the risk of adverse drug events (ADEs), drug-drug interactions and medication errors in the elderly [3, 4]. Previous studies have shown that drug-related problems (DRPs) are 
common. For example, in a study from Norway, $81 \%$ of the studied population had at least one DRP, and the most frequent types of DRP were non-optimal dose, need for laboratory tests, and non-optimal drug use [5]. Antithrombotic agents, non-steroidal anti-inflammatory drugs (NSAIDs), opioids, ACE inhibitors and corticosteroids for systemic use were the most frequent drug classes involved [5]. It is important to identify DRPs since they may increase the risk of hospitalisations. It has been estimated that up to $30 \%$ of hospital admissions in the older population may be related to medication problems [6].

Clinical pharmacy service is a patient-oriented activity including, for example, medication reviews or medication reconciliation [7]. Several studies suggest that pharmacistled interventions can improve patient outcomes such as the quality of prescription and drug-related readmissions [8-10], and some studies also indicate that pharmacist interventions can reduce hospital admissions and mortality [11-13].

The hospital studied is located in the sparsely populated inlands of northern Sweden. At the time of the present study, clinical pharmacy services were not established at the hospital and involvement of clinical pharmacists as a part of a ward team was very limited. Interviews conducted at the hospital before start of the study indicated that the nurses and physicians only had a vague idea about what services clinical pharmacists could provide. There was a general notion that clinical pharmacists could serve as educators or drug distributors, but only a few had a better understanding of the potential services that can be provided by clinical pharmacists [14].

The primary aim of this study was to investigate the prevalence and type of DRPs among patients admitted to a clinical pharmacist service-naïve medical ward at an inland hospital of northern Sweden. The secondary aim was to identify factors that may be associated with risk of DRPs.

\section{Methods}

\subsection{Study Population, Setting and Context}

During September-November 2015 and February-April 2016, 103 medication reviews were conducted by three clinical pharmacists at a general medical ward of the hospital. This inland hospital provides healthcare services for around 40,000 people living in this sparsely populated part of northern Sweden. It provides medical services for an area of the size of Switzerland and is the base of the ambulance helicopter [15]. There is no local hospital pharmacy to supply the hospital with drugs; these are transported 128 kilometres from the regional hospital. The medical ward contains 18 beds and the treatment covers a wide range of diseases, including many seriously ill patients.

The three clinical pharmacists conducting the interventions had previously worked with medication reviews for between 7 and 12 years in primary care and hospital wards at the time the study started. The clinical pharmacists attended the ward three days a week and participated in ward rounds on these days. All patients aged 18 years or older and admitted to the medical ward were eligible for the study and asked to participate. Exclusion criteria comprised patients with dementia, patients who did not speak Swedish, palliative patients and patients under the influence of alcohol and drugs.

\subsection{Data Extraction}

All data about the patients were collected from the medical records at the time the patients were admitted to the hospital. Basic demographic and medical data such as sex, age, serum creatinine, sodium, potassium and haemoglobin concentrations, drugs, medical history, living conditions, whether patients had multidose drug dispensing and whether they were taking over-the-counter (OTC) drugs or herbal remedies were collected. Renal function was assessed by calculating estimated glomerular filtration rate (eGFR) using the Cockcroft-Gault (CG) and Chronic Kidney Disease Epidemiology Collaboration (CKD-EPI) equations [16, 17]. Both equations were used since most recommendations published in dosage handbooks are based on eGFR estimated by the CG equation, while the CKDEPI equation is used by default to estimate GFR from serum creatinine measurement in the medical records in Västerbotten. When the number of drugs was calculated from the medical records, only the patients' ongoing medications were included. Pro re nata (PRN) drugs were not included, as information was lacking on the actual use of the drugs. Further, oxygen therapy and short-term antibiotic treatments were excluded. Simultaneous ordinations with identical drugs but at different dosages were counted as one drug.

\subsection{Medication Reviews}

The clinical pharmacy service provided by the clinical pharmacists on the ward consisted of medication reconciliation, medication review and participation in ward rounds. For every patient, a medication reconciliation was performed using information from the patient, from the medication list at the primary care centre and from the hospital medical record notes. When conducting a comprehensive medication review, the clinical pharmacists used all available data, including the medication list, list of laboratory results, medical record notes from primary care 
and index admission, as well as notes from earlier contact with healthcare providers. The clinical pharmacists identified relevant DRPs with respect to impairment of body function (renal function, liver function, contraindications, allergies, swallowing problems), certain drug use (toxic drugs, drugs prone to produce side effects, potentially inappropriate drugs), interactions (drug-drug and drugfood), symptoms (adverse drug reactions) and general judgement of the patient's drug use (proper drug selection, dosage, duration of treatment, polypharmacy, indication for therapy, untreated indication, adherence, OTC drugs, effectiveness and cost effectiveness).

Clinically relevant DRPs were discussed with the healthcare team during the ward rounds. A recommendation was given for each DRP, for example about drug selection, dosages and possible monitoring needs, with the attending physician making the final decision. The acceptance or rejection of the pharmacist's recommendation for changes in drug therapy was documented.

\subsection{Classification of Drug-Related Problems}

To investigate the prevalence of the DRPs, these were classified in twelve subgroups: unnecessary drug therapy, needs additional drug therapy, ineffective drug therapy, dosage too low, dosage too high, adverse drug reaction, non-compliance, inappropriate drug use, interaction, transition error, monitoring needed and other. This is a modified version of the classification system of Cipolle et al. [18]. The clinical pharmacists that performed the medication reviews classified the DRPs. Interactions were divided according to Janusmed interactions classification system [19]. Further, the actions taken in connection with the DRPs were sorted into categories (discontinuation of drug therapy, initiation of drug therapy, increase in dosage, reduction in dosage, change of drug, change of drug formulation, monitoring, written in the epicrisis [the responsible physician's summary of the patient's hospital stay], the physician does not accept the proposal, information to the physician and other). Drug classes and drugs involved in DRPs were also investigated.

\subsection{Data Analysis}

A regression analysis (simple and multiple logistic regression) was conducted to investigate the association between different factors and whether or not the patient had a DRP. These factors were sex, age, number of ongoing medications, renal function (CKD-EPI) and medical history. The most prevalent diagnoses among the study population were included in the analyses. A simple logistic regression was first conducted to determine significant values to include in the multiple logistic regression. The data are presented as odds ratios (ORs) with $95 \%$ confidence intervals (CIs). Background data are presented as averages and prevalence, while classification of DRPs and actions in relation to these are presented as prevalence. Statistical Package for the Social Sciences version 23 was used for all analyses.

\section{Results}

The study population consisted of 103 patients with a mean age of $77.3 \pm 10.3$, and $54(52.4 \%)$ of them were women. The most common diagnoses were hypertension $(50.5 \%)$, arrhythmias (25.2\%), heart failure (21.4\%) and cancer $(21.4 \%)$. At admission the patients had a mean of $7.9 \pm 3.6$ ongoing medications. Cardiovascular drugs (96.1\%), anticoagulants $(67.0 \%)$ and vitamins and minerals $(45.6 \%)$ were the most frequently used. According to the equation CKD-EPI, the mean eGFR in the population was $65.1 \pm$ $25.1 \mathrm{~mL} / \mathrm{min} / 1.73 \mathrm{~m}^{2}$, and 42 persons $(40.8 \%)$ had an eGFR $<60 \mathrm{~mL} / \mathrm{min} / 1.73 \mathrm{~m}^{2}$ (Table 1).

The clinical pharmacists identified 133 DRPs in $66 \%$ [68/103] of the study population. An average of 1.3 DRPs per patient was detected. Inappropriate drug use (29\%) was the most common DRP followed by interaction (16\%). Other DRPs were dosage too high (9\%), needs additional drug therapy (9\%), adverse drug reaction $(8 \%)$, non-compliance $(8 \%)$, unnecessary drug therapy $(5 \%)$, monitoring needed $(3 \%)$, transition error $(3 \%)$, dosage too low $(2 \%)$, ineffective drug $(1 \%)$ and other $(8 \%)$. The DRPs are specified in more detail in Table 2 . The mean time required for performing a medication review was $31.5 \mathrm{~min}$ per patient.

The physicians followed the advice of the clinical pharmacists in $88 \%(117 / 133)$ of the identified DRPs. These DRPs were thereby followed by an intervention, where discontinuation of drug therapy (33\%) and information $(15 \%)$ were most common. Other interventions that occurred in this study were change of drug (15\%), monitoring $(9 \%)$, reduction in dosage $(9 \%)$, initiation of drug therapy $(8 \%)$, other $(4 \%)$, increase in dosage $(3 \%)$, epicrisis $(2 \%)$ and change of drug formulation (1\%). Any changes in the prescriptions were made during the round.

In this study, 165 drugs contributed to 133 DRPs. The drug classes cardiovascular drugs $(n=27)$, psychotropic drugs $(n=20)$, analgesics and NSAIDs $(n=19)$ and vitamins/minerals $(n=19)$ caused DRPs most frequently. Specific drugs that most commonly occurred in DRPs were ibuprofen $(n=6)$, warfarin $(n=6)$, calcium $(n=5)$ and hydroxyzine $(n=5)$ (Table 3$)$.

DRPs were more frequently present in older patients (OR 1.062 [95\% CI 1.017-1.108]), patients taking a higher number of drugs (OR 1.478 [95\% CI 1.236-1.768]) and 
Table 1 Patients' characteristics

\begin{tabular}{|c|c|}
\hline Characteristics & Total $(N=103)$ \\
\hline Women, no. (\%) & $54(52.4)$ \\
\hline Age, mean $\pm \mathrm{SD}$, years & $77.3 \pm 10.3$ \\
\hline \multicolumn{2}{|l|}{ Living arrangements, $n=68$} \\
\hline Living at home $(\%)$ & $64(62.1)$ \\
\hline Nursing home $(\%)$ & $4(3.9)$ \\
\hline Number of ongoing medications at admission, mean \pm SD & $7.9 \pm 3.6$ \\
\hline Multidose drug dispensing $(\%), n=78$ & $11(10.7)$ \\
\hline $\mathrm{OTC}^{\mathrm{a}}(\%), n=75$ & $36(35.0)$ \\
\hline Herbal remedies $^{\mathrm{b}}(\%), n=72$ & $5(4.9)$ \\
\hline \multicolumn{2}{|l|}{ Estimated GFR } \\
\hline $\mathrm{CKD}-\mathrm{EPI}$, mean $\pm \mathrm{SD}, \mathrm{mL} / \mathrm{min} / 1.73 \mathrm{~m}^{2}$ & $65.1 \pm 25.1$ \\
\hline Cockcroft-Gault, mean $\pm \mathrm{SD}, \mathrm{mL} / \mathrm{min}, n=88$ & $66.1 \pm 34.9$ \\
\hline CKD-EPI $<60 \mathrm{~mL} / \mathrm{min} / 1.73 \mathrm{~m}^{2}(\%)$ & $42(40.8)$ \\
\hline \multicolumn{2}{|l|}{ Laboratory values } \\
\hline $\mathrm{Hb}$, mean $\pm \mathrm{SD}, \mathrm{g} / \mathrm{L}, n=99$ & $122.8 \pm 23.0$ \\
\hline $\mathrm{S}$-potassium, mean $\pm \mathrm{SD}, \mathrm{mmol} / \mathrm{L}, n=98$ & $4.0 \pm 0.6$ \\
\hline $\mathrm{S}$-sodium, mean $\pm \mathrm{SD}, \mathrm{mmol} / \mathrm{L}, n=100$ & $138 \pm 25.1$ \\
\hline \multicolumn{2}{|l|}{ Medical history, $n(\%)$} \\
\hline Hypertension & $52(50.5)$ \\
\hline Arrhythmias & $26(25.2)$ \\
\hline Heart failure & $22(21.4)$ \\
\hline Cancer & $22(21.4)$ \\
\hline Diabetes mellitus & $18(17.5)$ \\
\hline Ischaemic heart disease & $17(16.5)$ \\
\hline Chronic obstructive pulmonary disease & 15 (14.6) \\
\hline Stroke/TIA & $10(9.7)$ \\
\hline Depression & $3(2.9)$ \\
\hline \multicolumn{2}{|l|}{ Drug classes, $n(\%)$} \\
\hline Cardiovascular drugs & $99(96.1)$ \\
\hline Anticoagulants & $69(67.0)$ \\
\hline Vitamins and minerals & $47(45.6)$ \\
\hline Analgesic drugs & $39(37.9)$ \\
\hline Psychotropic drugs & $28(27.2)$ \\
\hline Drugs for obstructive pulmonary disease & $22(21.4)$ \\
\hline Anti-diabetic drugs & $21(20.4)$ \\
\hline Urogenital drugs & $8(7.8)$ \\
\hline Antiepileptic drugs & $2(1.9)$ \\
\hline
\end{tabular}

All data about the patients were collected from the medical records at the time the patients were admitted to the hospital

a OTC drugs were, for example, paracetamol, NSAID and vitamins in the study

b Herbal remedies included ginseng, omega 3 and dried nettles

$C K D$-EPI Chronic Kidney Disease Epidemiology Collaboration, GFR glomerular filtration rate, $H b$ haemoglobin, $O T C$ over the counter, $S D$ standard deviation, TIA transient ischaemic attack

patients with reduced renal function (OR 0.979 [95\% CI, 0.962-0.997]). No associations were found between DRPs and any medical history or gender. In the multivariate model, only the number of ongoing medications (OR 1.439 [95\% CI 1.197-1.729]) was still significant (Table 4).

\section{Discussion}

This study showed that the proportion of patients with DRPs was high, and that the most common DRPs were inappropriate drug use and interactions. The acceptance 
Table 2 Drug-related problems identified by clinical pharmacists

\begin{tabular}{|c|c|c|c|}
\hline Type of DRP & Identified problem & $\begin{array}{l}\text { No. of DRPs } \\
\text { (no. acted } \\
\text { upon) }\end{array}$ & Drugs involved (frequency) \\
\hline \multirow{10}{*}{$\begin{array}{l}\text { Adverse drug } \\
\quad \text { reaction }(n=11)\end{array}$} & Anaemia, thrombocytopenia & $1(1)$ & [Leflunomide, methotrexate] \\
\hline & Blurred vision & $1(1)$ & {$[$ Paracetamol + codeine $]$} \\
\hline & Oedema & $1(1)$ & Felodipine \\
\hline & Heart failure & $1(1)$ & Celecoxib \\
\hline & Hypokalaemia & $1(1)$ & [Candesartan + hydrochlorthiazide] \\
\hline & Hyponatremia & $1(1)$ & Enalapril \\
\hline & Nausea and fatigue & $2(2)$ & Digoxin (2) \\
\hline & Reduced renal function & $1(1)$ & Mesalazine \\
\hline & $\begin{array}{l}\text { Repeated urinary tract } \\
\text { infections }\end{array}$ & $1(1)$ & Saxagliptin \\
\hline & Tremors & $1(1)$ & [Formoterol, tiotropium bromide] \\
\hline $\begin{array}{l}\text { Dosage too high } \\
\quad(n=12)\end{array}$ & $\begin{array}{l}\text { Dosage too high according } \\
\text { to indication or guidelines }\end{array}$ & $12(11)$ & $\begin{array}{l}\text { Candesartan, cefotaxime, ciprofloxacin, digoxin, esomeprazole, folic } \\
\text { acid (2), gabapentin, hydroxyzine, ipratropium, metformin, } \\
\text { rivaroxaban }\end{array}$ \\
\hline $\begin{array}{l}\text { Dosage too low } \\
(n=3)\end{array}$ & $\begin{array}{l}\text { Dosage too low according to } \\
\text { indication or guidelines }\end{array}$ & $3(3)$ & Budesonide inhaler, cefotaxime, pregabalin \\
\hline \multirow{14}{*}{$\begin{array}{l}\text { Inappropriate drug } \\
\quad(n=39)\end{array}$} & Allergy & $1(1)$ & Flucloxacillin \\
\hline & \multicolumn{3}{|l|}{ Diagnoses } \\
\hline & Asthma & $1(0)$ & Metoprolol \\
\hline & Arrhythmia & $4(2)$ & [Bromhexine + ephedrine], SSRI, indacaterol, salmeterol \\
\hline & Heart failure & $2(2)$ & [Diclofenac + misoprostol], NSAID \\
\hline & $\begin{array}{l}\text { Drugs that should be } \\
\text { avoided in the elderly }\end{array}$ & $14(12)$ & $\begin{array}{l}\text { Diazepam (2), flunitrazepam, flupentixol, hydroxyzine (2), propiomazine } \\
\text { (3), [propiomazine, zolpidem], tramadol, zolpidem (2) }\end{array}$ \\
\hline & Inappropriate analgesic drug & $1(1)$ & Oxycodone (short acting) \\
\hline & $\begin{array}{l}\text { Inappropriate drug } \\
\text { according to guidelines }\end{array}$ & $2(1)$ & Dihydroergotamine, quinine \\
\hline & $\begin{array}{l}\text { Inappropriate drug } \\
\text { according to renal function }\end{array}$ & $9(8)$ & $\begin{array}{l}\text { Acetylcysteine (effervescent tablets), atenolol, glibenclamide, glucose- } \\
\text { Na-K, morphine, NSAID (4) }\end{array}$ \\
\hline & $\begin{array}{l}\text { Inappropriate drug } \\
\text { according to treatment } \\
\text { time }\end{array}$ & $1(1)$ & Metoclopramide \\
\hline & $\begin{array}{l}\text { Inappropriate drug when } \\
\text { opioid treated }\end{array}$ & $1(1)$ & Sterculia \\
\hline & Inappropriate formulation & $1(1)$ & Paracetamol \\
\hline & $\begin{array}{l}\text { Several prescriptions of the } \\
\text { same drug }\end{array}$ & $1(1)$ & Carvedilol \\
\hline & Wrong diagnosis & $1(1)$ & B vitamins \\
\hline $\begin{array}{l}\text { Ineffective drug } \\
\quad(n=1)\end{array}$ & Low GFR & $1(1)$ & Thiazide \\
\hline \multirow{8}{*}{$\begin{array}{r}\text { Interaction } \\
(n=21)\end{array}$} & $\mathrm{C}$ interactions & $12(11)$ & Esomeprazole-doxycycline \\
\hline & & & Levothyroxine-calcium + vitamin D (2) \\
\hline & & & Magnesium-iron \\
\hline & & & Methotrexate-phenoxymethylpencillin \\
\hline & & & NSAID-rivaroxaban \\
\hline & & & NSAID-ticagrelor (2) \\
\hline & & & SSRI-ASA \\
\hline & & & Ticagrelor-simvastatin \\
\hline
\end{tabular}


Table 2 continued

\begin{tabular}{|c|c|c|c|}
\hline Type of DRP & Identified problem & $\begin{array}{l}\text { No. of DRPs } \\
\text { (no. acted } \\
\text { upon) }\end{array}$ & Drugs involved (frequency) \\
\hline & & & Warfarin-erythromycin \\
\hline & & & Warfarin-omega 3 \\
\hline & D interactions & $4(3)$ & Ciprofloxacin-calcium + vitamin D \\
\hline & & & Hydroxyzine-flecainide \\
\hline & & & SSRI-ciprofloxacin \\
\hline & & & Warfarin-ASA \\
\hline & $\mathrm{C}$ and $\mathrm{D}$ interaction & $1(1)$ & Hydroxyzine-SSRI-omeprazole \\
\hline & Unspecified & $4(4)$ & Dabrafenib-fentanyl \\
\hline & & & Dabrafenib-omeprazole \\
\hline & & & Warfarin-herbal remedy (2) \\
\hline \multirow{5}{*}{$\begin{array}{l}\text { Monitoring needed } \\
\quad(n=4)\end{array}$} & Laboratory value & & \\
\hline & $\mathrm{CO}_{2}$ tot & $1(1)$ & Acetazolamide \\
\hline & General blood sample & $1(1)$ & Several drugs \\
\hline & $\mathrm{HbA1c}$ & $1(1)$ & Repaglinide \\
\hline & Thyroid status & $1(1)$ & Levothyroxine \\
\hline \multirow{7}{*}{$\begin{array}{l}\text { Need additional } \\
\text { drug therapy } \\
(n=12)\end{array}$} & Heart failure & $1(0)$ & Spironolactone \\
\hline & Homocysteine elevated & $1(1)$ & Folic acid \\
\hline & Increased risk of obstipation & $4(4)$ & Laxative, morphine without laxatives (3) \\
\hline & Increased risk of ulcus & $3(2)$ & $\begin{array}{l}\text { [Bortezomib, clopidogrel and deltisone without PPI], [dalteparin and } \\
\text { prednisolone without PPI], [prednisolone and warfarin without PPI] }\end{array}$ \\
\hline & Myocardial infarction & $1(1)$ & Enalapril \\
\hline & PTH elevated & $1(0)$ & Alfacalcidol \\
\hline & S-ferritin low & $1(1)$ & Iron \\
\hline \multirow[t]{5}{*}{$\begin{array}{l}\text { Non-compliance } \\
\quad(n=10)\end{array}$} & $\begin{array}{l}\text { Handling problems- } \\
\text { inhalation technique }\end{array}$ & $2(1)$ & $\begin{array}{l}\text { [Budesonide }+ \text { formoterol, terbutaline], [fluticasone }+ \text { salmeterol, } \\
\text { tiotropium bromide] }\end{array}$ \\
\hline & $\begin{array}{l}\text { Medication is not taken } \\
\text { according to the } \\
\text { medication list }\end{array}$ & $1(1)$ & Several drugs \\
\hline & $\begin{array}{l}\text { Overuse compared to the } \\
\text { prescription }\end{array}$ & $1(1)$ & Formoterol \\
\hline & $\begin{array}{l}\text { The medicine is taken } \\
\text { according to an old } \\
\text { prescription }\end{array}$ & $1(1)$ & Methotrexate \\
\hline & $\begin{array}{l}\text { Underuse compared with the } \\
\text { prescription }\end{array}$ & $5(5)$ & $\begin{array}{l}\text { [Budesonide }+ \text { formoterol, tiotropium bromide], [eplerenone, } \\
\text { furosemide, lerkanidipine], [ipratropium, simvastatin], iron, ticagrelor }\end{array}$ \\
\hline \multirow[t]{2}{*}{$\begin{array}{l}\text { Transition error } \\
\quad(n=4)\end{array}$} & $\begin{array}{l}\text { Wrong dose or time of dose } \\
\text { in medical records }\end{array}$ & $3(2)$ & Isorbide mononitrate, levothyroxine, methotrexate \\
\hline & $\begin{array}{l}\text { Wrong information about } \\
\text { the drug in medical } \\
\text { records }\end{array}$ & $1(1)$ & Ezetimibe \\
\hline $\begin{array}{c}\text { Unnecessary drug } \\
\text { therapy }(n=6)\end{array}$ & No indication & $6(5)$ & $\begin{array}{l}\text { Calcium + vitamin D, omeprazole, potassium, prednisolone, } \\
\text { simvastatin, [vitamin B12, folic acid, pyridoxine] }\end{array}$ \\
\hline
\end{tabular}


Table 2 continued

\begin{tabular}{|c|c|c|c|}
\hline Type of DRP & Identified problem & $\begin{array}{l}\text { No. of DRPs } \\
\text { (no. acted } \\
\text { upon) }\end{array}$ & Drugs involved (frequency) \\
\hline Other $(n=10)$ & & $10(10)$ & $\begin{array}{l}\text { Abnormal laboratory value detected (high } \mathrm{MCV} \text {, low } \mathrm{Hb} \text { ) (2), [ACE } \\
\text { inhibitor, ARB], amlodipine, calcium, calcium + vitamin D, } \\
\text { metformin, metoprolol, spironolactone, sterculia }\end{array}$ \\
\hline
\end{tabular}

Drugs in square brackets were counted as one DRP in the medication reviews. Plus symbols were used to indicate combination medications. Interactions were divided according to Janusmed interactions classification system [19]. C interactions were considered clinically significant but manageable, and D interactions were considered clinically significant and should be avoided [19]. The category 'other' included DRPs concerning wrong formulation and patient's request about treatment choice, for example

$A C E$ angiotensin-converting enzyme, $A R B$ angiotensin receptor blocker, $A S A$ acetylsalicylic acid, $D R P$ drug-related problem, $G F R$ glomerular filtration rate, $H b$ haemoglobin, $M C V$ mean corpuscular volume, NSAIDs non-steroidal anti-inflammatory drugs, $P P I$ proton pump inhibitor, $P T H$ parathyroid hormone, SSRI selective serotonin reuptake inhibitor

rate of the clinical pharmacists' suggestions was high, at 88\%. Discontinuation of drug therapy and information were the most frequent interventions. The drug classes cardiovascular drugs, psychotropic drugs, analgesics/ NSAIDs and vitamins/minerals were most commonly involved in DRPs. Specific drugs most commonly involved were ibuprofen, warfarin, calcium and hydroxyzine. DRPs were more frequently present in older patients, patients taking a higher number of drugs and patients with reduced renal function. In the multivariate model, only the number of ongoing medications was still significant.

In previous research, both the proportion of patients with DRPs and the average number of DRPs per person were in line with or higher than the results in this study. For example, studies have reported proportions of patients with DRPs of $81 \%$, and the number of DRPs per person as 2.1 and 3.7 per patient compared with 1.3 DRPs per person in the present study $[5,20]$. However, these numbers are difficult to compare. Patients with dementia were excluded when this study was conducted and DRPs are common in this specific patient group [21,22]. Also, information about OTC and herbal remedies was missing in some cases, which might have contributed to under-reporting of DRPs. Other methodological choices, such as whether only clinically relevant DRPs or all DRPs were included, and whether the study was conducted at a hospital or in primary care, can also explain the differences in the results. How DRP was defined is also one aspect to consider; for example, in this study, when a patient had difficulties with inhalation technique and several drugs were involved, it was still counted as one DRP.

The most frequently occurring DRPs were inappropriate drug use and interactions. Similar results have been shown in previous research, where non-optimal dose, non-optimal drug and drug-drug interaction have been identified as common DRPs $[5,20]$. In the inappropriate drug use category, the subgroups 'inappropriate drug according to renal function' and 'drugs that should be avoided in the elderly' were dominant. The fact that reduced renal function can result in inappropriate drug use has been shown previously $[23,24]$. In this study, several patients used OTC NSAIDs, which can lead to impaired renal perfusion and acute renal failure [25]. Further, drugs that should be avoided in the elderly because of pharmacokinetics and pharmacodynamics that change with age $[4,26]$ were common in this study. One example is propiomazine, which may cause daytime sleepiness and extrapyramidal side effects in these patients [4]. Drug-drug interactions can cause adverse drug reactions, but can also lead to hospital admissions according to previous research [27]. The DRP adverse drug reaction has previously received much attention in healthcare, although other DRPs are equally important [5]. In this context, it is possible that multiprofessional healthcare teams can contribute to a more comprehensive view on problems related to the patient's drug use.

The physicians followed the advice of the clinical pharmacists in $88 \%$ of the identified DRPs, and these DRPs were then followed by an intervention. The proportion of cases that led to interventions is very inconsistent in different studies. Two studies reported considerably lower values (56\% and 69\%), while one study had about the same proportion (93\%) of interventions as shown in this study $[20,28,29]$. The high proportion of suggestions that were accepted by the physicians in the present study is interesting since the personnel at the hospital only had a vague idea about what pharmacists can and are allowed to do [14]. This may indicate that the pharmacists' suggestions were clinically relevant, but also that the pharmacists working on the ward were highly experienced. The most common intervention, discontinuation of drug therapy, was consistent with previous research [20].

The drug classes cardiovascular drugs, psychotropic drugs, analgesic drugs/NSAIDs and vitamins/minerals caused DRPs most frequently in this study. Similar results have been observed previously [5, 20, 30]. In addition, previous research shows that cardiovascular and psychotropic 
Table 3 Drug classes and drugs involved in drug-related problems

\begin{tabular}{|c|c|c|}
\hline Drug class (no.) & $\begin{array}{l}\text { Frequency } \\
(\%)\end{array}$ & Drugs (no.), $N=165$ \\
\hline Analgesic drugs and NSAIDs & $19(11.5)$ & \\
\hline NSAID and combinations (10) & & Celecoxib (1), diclofenac (1), diclofenac + misoprostol (1), diflunisal (1), ibuprofen (6) \\
\hline Opioid analgesic (7) & & Fentanyl (1), morphine (4), oxycodone (1), tramadol (1) \\
\hline Paracetamol + codeine $(2)$ & & Paracetamol (1), paracetamol + codeine (1) \\
\hline Antibacterials for systemic use & $9(5.5)$ & $\begin{array}{l}\text { Cefotaxime (2), ciprofloxacin (3), doxycycline (1), erythromycin (1), flucloxacillin (1), } \\
\text { phenoxymethylpencillin (1) }\end{array}$ \\
\hline Antiepileptic drugs & $2(1.2)$ & Gabapentin (1), pregabalin (1) \\
\hline Antithrombotic agents & $16(9.7)$ & ASA (2), clopidogrel (1), dalteparin (1), rivaroxaban (2), ticagrelor (4), warfarin (6) \\
\hline Cardiovascular drugs & $27(16.4)$ & \\
\hline $\begin{array}{l}\text { Agents acting on the renin- } \\
\text { angiotensin system ( } 7 \text { ) }\end{array}$ & & $\begin{array}{l}\text { Candesartan (1), candesartan + hydrochlorthiazide (1), enalapril (3), eplerenone (1), losartan } \\
\text { (1) }\end{array}$ \\
\hline$\beta$-blocking agents (4) & & Atenolol (1), carvedilol (1), metoprolol (2) \\
\hline Calcium channel blockers (3) & & Amlodipine (1), felodipine (1), lerkanidipine (1) \\
\hline Diuretics (4) & & Bendroflumethiazide (1), furosemide (1), spironolactone (2) \\
\hline Other cardiovascular drugs (9) & & Digoxin (3), ezetimibe (1), flecainide (1), isosorbide mononitrate (1), simvastatin (3) \\
\hline $\begin{array}{l}\text { Drugs for obstructive airway } \\
\text { diseases }\end{array}$ & $14(8.5)$ & $\begin{array}{l}\text { Budesonide (1), budesonide }+ \text { formoterol (2), fluticasone }+ \text { salmeterol (1), formoterol (2), } \\
\text { indacaterol (1), ipratropium (2), salmeterol (1), terbutaline (1), tiotropium bromide (3) }\end{array}$ \\
\hline Drugs used in diabetes & $5(3.0)$ & Glibenclamide (1), metformin (2), repaglinide (1), saxagliptin (1) \\
\hline Psychotropic drugs & $20(12.1)$ & \\
\hline Antidepressant drugs (4) & & Citalopram (4) \\
\hline Antipsychotics (1) & & Flupentixol (1) \\
\hline Anxiolytics, hypnotics and & & Diazepam (2), flunitrazepam (1), hydroxyzine (5), propiomazine (4), zolpidem (3) \\
\hline
\end{tabular}

Alfacalcidol (1), B-vitamins (1), folic acid (4), pyridoxine (1), vitamin B12 (1)

Calcium (1), calcium + vitamin D (5), iron (3), magnesium (1), potassium (1)

combinations (11)

Other

Drugs only mentioned as a drug class (proton inhibitors and laxatives) in the medication reviews were excluded. Plus symbols were used to indicate combination medications. Furthermore, unspecified drugs (e.g. mentioned as 'several drugs') were excluded. No drug was included when an abnormal laboratory value was detected and the value could not be derived from any of the medications the patient was currently taking ASA acetylsalicylic acid, NSAIDs nonsteroidal anti-inflammatory drugs

drugs contribute to hospitalisations due to adverse events in older people [6]. Commonly prescribed drugs are of course more likely to be involved in DRPs. In this study, 99 patients were prescribed cardiovascular drugs, and 27 DRPs were found to be associated with this drug class (28\%). According to the present findings, psychotropic drugs may run a higher risk of causing DRPs; 20 DRPs were found among 28 persons with this drug class $(71 \%)$.

NSAIDs contributed to DRPs to an unexpected extent, regarding the known serious side effects such as heart failure and gastrointestinal bleeding [31, 32]. It would be desirable for these problems to be identified earlier in the healthcare chain.
In this study, ibuprofen, warfarin, calcium and hydroxyzine were the specific drugs most frequently involved in DRPs. These drugs, except hydroxyzine, also caused DRPs in previous research. Although hydroxyzine was not included as a specific substance in previous research, the association between DRPs and the drug class of anxiolytics has been observed [5, 20, 30]. The drugs that contributed most frequently to DRPs in this study can be attributed to different explanations. Hydroxyzine is an inappropriate drug for the elderly and can cause cognitive impairment because of its anticholinergic characteristics [4]. Warfarin has serious adverse events and interacts with several other substances. In the present study, a drug interaction between 
Table 4 Characteristics of the population with and without drug-related problems

\begin{tabular}{|c|c|c|c|c|}
\hline & $\begin{array}{l}\text { Drug-related } \\
\text { problems }\end{array}$ & $\begin{array}{l}\text { Non-drug-related } \\
\text { problems }\end{array}$ & $\begin{array}{l}\text { Simple OR }(95 \% \\
\text { CI })\end{array}$ & $\begin{array}{l}\text { Multiple OR }(95 \% \\
\text { CI) }\end{array}$ \\
\hline Cases $n(\%)$ & $68(66)$ & $35(34)$ & & \\
\hline Women $n(\%)$ & $38(55.9)$ & $16(45.7)$ & $1.504(0.066-3.413)$ & \\
\hline Mean age \pm SD & $79.4 \pm 8.65$ & $73.3 \pm 12.13$ & $1.062(1.017-1.108)$ & $1.047(0.989-1.109)$ \\
\hline $\begin{array}{l}\text { Number of ongoing medications on } \\
\text { admission } \pm \text { SD }\end{array}$ & $9.1 \pm 3.4$ & $5.5 \pm 2.6$ & $1.478(1.236-1.768)$ & $1.439(1.197-1.729)$ \\
\hline Estimated GFR $\left(\mathrm{mL} / \mathrm{min} / 1.73 \mathrm{~m}^{2}\right) \pm \mathrm{SD}$ & $61.0 \pm 26.5$ & $73.0 \pm 20.2$ & $0.979(0.962-0.997)$ & $1.004(0.980-1.030)$ \\
\hline \multicolumn{5}{|l|}{ Medical history } \\
\hline Hypertension $n(\%)$ & $36(52.9)$ & $16(45.7)$ & $1.336(0.590-3.027)$ & \\
\hline Arrhythmias $n(\%)$ & $21(30.9)$ & $5(14.3)$ & $2.681(0.913-7.875)$ & \\
\hline Cancer $n(\%)$ & $18(26.5)$ & $4(11.4)$ & $2.790(0.864-9.011)$ & \\
\hline Heart failure $n(\%)$ & $17(25.0)$ & $5(14.3)$ & $2.000(0.670-5.975)$ & \\
\hline Diabetes mellitus $n(\%)$ & $14(20.6)$ & $4(11.4)$ & $2.009(0.608-6.643)$ & \\
\hline Ischaemic heart disease $n(\%)$ & $12(17.6)$ & $5(14.3)$ & $1.286(0.414-3.995)$ & \\
\hline Chronic respiratory diseases $n(\%)$ & $11(16.2)$ & $4(11.4)$ & $1.496(0.439-5.092)$ & \\
\hline Stroke/TIA $n(\%)$ & $6(8.8)$ & $4(11.4)$ & $0.750(0.197-2.855)$ & \\
\hline
\end{tabular}

Creatinine clearance was based on the Chronic Kidney Disease Epidemiology Collaboration (CKD-EPI) equation. The multivariate model includes significant variables from the simple OR

$C I$ confidence interval, GFR glomerular filtration rate, $O R$ odds ratio, SD standard deviation, TIA transient ischaemic attack

warfarin and a herbal remedy was found in two patients. Calcium interacts with commonly used drugs such as ciprofloxacin and levothyroxine if given simultaneously, and this was also seen in this study [4, 19]. Ibuprofen is included in the NSAID group and can be problematic as described above.

According to the simple logistic regression analysis in this study, DRPs were more frequently present in older patients, patients with reduced renal function and patients taking a higher number of drugs. The finding of higher age as a factor associated with DRPs is in line with previous studies [33, 34]. Further, reduced renal function has been shown in previous studies to be a risk factor for DRPs $[35,36]$. The number of drugs was the only associated factor remaining significant in the multivariate model. This result is in accordance with previous studies and the National Board of Health and Welfare in Sweden [4, 5, 34]. The complexity of polypharmacy causes problems for patients and provides a considerable challenge for healthcare professionals. In previous studies, an increased risk of adverse drug reactions, interactions and reduced compliance has been observed in patients taking a high number of drugs $[6,37,38]$. However, although the number of drugs is associated with DRPs, it can also be important to evaluate drug lists containing few drugs [39]. In this study, for example, one patient with only three ongoing medications used NSAIDs in combination with ticagrelor, which increases the risk of internal bleeding [19].
One limitation of this study is that the patients were not included consecutively, since the clinical pharmacists were not present in the hospital for the entire study period. Also, the patient population in this study was small. This can lead to non-significant results and problems with generalisability. All involved pharmacists performed comprehensive medication reviews as described in the methods section. Still, limitations in the inter-rater reliability cannot be ruled out. Also, we did not evaluate if the DRPs detected by the clinical pharmacists were clinically relevant and significant. Under certain circumstances, physicians may take calculated risks of potentially causing DRPs when there is lack of better alternatives or when the benefits outweigh any risks. However, based on the high acceptance rate of proposed medication changes $(88 \%)$, it appears reasonable to assume that most of the DRPs were also judged to be relevant by the physician in charge. Finally, the lack of control group is a limitation of the present study, which should be borne in mind.

There are also strengths with the method used in this study. DRPs were discussed in multidisciplinary healthcare teams, which may have resulted in a higher rate of interventions to the DRPs due to face-to-face conversations. The clinical pharmacists involved in this study have long experience within the subject area and they had access to medical records and laboratory values, so the conditions for analysing DRPs among the patients were good. The pharmacist service-naïve environment and the unique location 
of the hospital are interesting, and few, if any, previous similar studies have been conducted in this context.

\section{Conclusion}

Drug-related problems were commonly observed among patients admitted to the medical ward. Medication reviews conducted by clinical pharmacists as part of a ward team resulted in several interventions to improve the patients' drug treatment.

Author Contributions M. Gustafsson was responsible for the study concept and design and performed the statistical analyses. C. Peterson and M. Gustafsson interpreted the data and C. Peterson prepared the manuscript. All authors carried out a critical revision of the manuscript, contributed with comments and approved the final version.

\section{Compliance with Ethical Standards}

Funding None.

Conflicts of interest C. Peterson and M. Gustafsson declare that they have no conflict of interests.

Ethical approval The study was approved by Regional Ethical Review Board in Umeå (registration number: 2014/322-31Ö). Informed consent was obtained from all individual participants included in the study.

Open Access This article is distributed under the terms of the Creative Commons Attribution-NonCommercial 4.0 International License (http://creativecommons.org/licenses/by-nc/4.0/), which permits any noncommercial use, distribution, and reproduction in any medium, provided you give appropriate credit to the original author(s) and the source, provide a link to the Creative Commons license, and indicate if changes were made.

\section{References}

1. Wettermark B. Läkemedelsanvändningen i befolkningen [Eng. The drug use in the population]. Janusinfo; 2010. http://www. janusinfo.se/Documents/Ojamlik-underbehandling/L\%C3\% A4kemedelsanv\%C3\%A4ndningen-i-befolkningen.pdf. Accessed 19 Oct 2016

2. Walker R, Whittlesea C. Clinical pharmacy and therapeutics, 5th ed. Vol. Edinburgh: Elsevier Ltd; 2012. p. 2-7, 149-151.

3. Caratozzolo S, Gipponi S, Marengoni A, et al. Potentially serious drug-drug interactions in older patients hospitalized for acute ischemic and hemorrhagic stroke. Eur Neurol. 2016;76:161-6.

4. Indikatorer för god läkemedelsterapi hos äldre [Eng. Indicators for evaluating the quality of older people's drug therapy]. The National Board of Health and Welfare; 2010. http://www. socialstyrelsen.se/Lists/Artikelkatalog/Attachments/18085/20106-29.pdf. Accessed 19 Oct 2016.

5. Blix HS, Viktil KK, Reikvam $\AA$, et al. The majority of hospitalised patients have drug-related problems: results from a prospective study in general hospitals. Eur J Clin Pharmacol. 2004;60:651-8
6. Salvi F, Marchetti A, D'Angelo F, et al. Adverse drug events as a cause of hospitalization in older adults. Drug Saf. 2012;35:29-45.

7. Ahmed SI, Hasan SS, Hassali MA. Clinical pharmacy and pharmaceutical care: a need to homogenize the concepts. Am J Pharm Educ. 2010;74:193g.

8. Gustafsson M, Sjölander M, Pfister B et al. Pharmacist participation in hospital ward teams and hospital readmission rates among people with dementia: a randomized controlled trial. Eur J Clin Pharmacol. 2017. doi:10.1007/s00228-017-2249-8.

9. Graabæk T, Kjeldsen LJ. Medication reviews by clinical pharmacists at hospitals lead to improved patient outcomes: a systematic review. Basic Clin Pharmacol Toxicol. 2013;112:359-73.

10. Nkansah N, Mostovetsky O, Yu C, et al. Effect of outpatient pharmacists' non-dispensing roles on patient outcomes and prescribing patterns. Cochrane Database Syst Rev. 2010;7:CD000336.

11. Lee JK, Slack MK, Martin J, Ehrman C, Chisholm-Burns M, et al. Geriatric patient care by U.S. pharmacists in healthcare teams: systematic review and meta-analyses. J Am Geriatr Soc. 2013;61:1119-27.

12. Jiang S-P, Zhu Z-Y, Ma K-F, et al. Impact of pharmacist antimicrobial dosing adjustments in septic patients on continuous renal replacement therapy in an intensive care unit. Scand J Infect Dis. 2013;45:891-9.

13. Salgado TM, Moles R, Benrimoj SI, et al. Pharmacists' interventions in the management of patients with chronic kidney disease: a systematic review. Nephrol Dial Transplant. 2012;27:276-92.

14. Sjölander M, Gustafsson M, Gallego G. Doctors' and nurses' perceptions of a ward-based pharmacist in rural northern Sweden. Int J Clin Pharm. doi:10.1007/s11096-017-0488-5.

15. Lycksele lasarett [Eng. Lycksele hospital]. http://www.vll.se/ startsida/halsa-och-vard/vara-sjukhus/lycksele-lasarett. Accessed 23 Oct 2016.

16. Cockcroft DW, Gault MH. Prediction of creatinine clearance from serum creatinine. Nephron. 1976;16:31-41.

17. Levey AS, Stevens LA, Schmid CH, et al. A new equation to estimate glomerular filtration rate. Ann Intern Med. 2009;150:604-12.

18. Cipolle R, Strand L, Morely P. Pharmaceutical Care Practice. 2nd ed. New York: The McGraw-Hill Companies inc; 2004. p. 13.

19. Stockholm County Council, the Health and Medical Care Administration. Janusmed interactions. Available at: https:// janusmed.sll.se/interaktioner. Accessed 19 Oct 2016.

20. Brulhart MI, Wermeille JP. Multidisciplinary medication review: evaluation of a pharmaceutical care model for nursing homes. Int J Clin Pharm. 2011;33:549-57.

21. Kaufmann CP, Stämpfli D, Hersberger KE, et al. Determination of risk factors for drug-related problems: a multidisciplinary triangulation process. BMJ Open. 2015;5:e006376.

22. Gustafsson M, Sjölander M, Pfister B, et al. Drug- related hospital admissions among old people with dementia. Eur J Clin Pharmacol. 2016;72:1143-53.

23. Khanal A, Peterson G, Castelino R, et al. Potentially inappropriate prescribing of renally cleared drugs in elderly patients in community and aged care settings. Drugs Aging. 2015;32:391-400

24. Sönnerstam E, Sjölander M, Gustafsson M. Inappropriate prescription and renal function among older patients with cognitive impairment. Drugs Aging. 2016;12:1-11.

25. Walter $H$. Nonsteroidal anti-inflammatory drugs and the kidney. Pharmaceuticals. 2010;3:2291-321.

26. Mangoni AA, Jackson SHD. Age-related changes in pharmacokinetics and pharmacodynamics: basic principles and practical applications. Br J Clin Pharmacol. 2004;57:6-14. 
27. Juurlink DN, Mamdani M, Kopp A, et al. Drug-drug interactions among elderly patients hospitalized for drug toxicity. JAMA. 2003;289:1652-8.

28. Milos V, Rekman E, Bondesson $\AA$, et al. Improving the quality of pharmacotherapy in elderly primary care patients through medication reviews: a randomised controlled study. Drugs Aging. 2013;30:235-46.

29. Chau SH, Jansen APD, Ven PM, et al. Clinical medication reviews in elderly patients with polypharmacy: a cross-sectional study on drug-related problems in the Netherlands. Int J Clin Pharm. 2016;38:46-53.

30. Kjeldsen LJ, Birkholm T, Fischer H, et al. Characterization of drug-related problems identified by clinical pharmacy staff at Danish hospitals. Int J Clin Pharm. 2014;36:734-41.

31. Ungprasert P, Srivali N, Thongprayoon C. Nonsteroidal anti-inflammatory drugs and risk of incident heart failure: a systematic review and meta-analysis of observational studies. Clin Cardiol. 2016;39:111-8.

32. Langman MJS, Weil J, Wainwright $P$, et al. Risks of bleeding peptic ulcer associated with individual non-steroidal anti-inflammatory drugs. The Lancet. 1994;343:1075-8.

33. Al Hamid A, Ghaleb M, Aljadhey H, et al. A systematic review of hospitalization resulting from medicine-related problems in adult patients. Br J Clin Pharmacol. 2014;78:202-17.
34. Urbina O, Ferrández O, Grau S, et al. Design of a score to identify hospitalized patients at risk of drug-related problems. Pharmacoepidemiol Drug Saf. 2014;23:923-32.

35. Belaiche S, Romanet T, Allenet B, et al. Identification of drugrelated problems in ambulatory chronic kidney disease patients: a 6-month prospective study. J Nephrol. 2012;25:782-8.

36. Blix HS, Viktil KK, Moger TA, et al. Use of renal risk drugs in hospitalized patients with impaired renal function-an underestimated problem? Nephrol Dial Transpl. 2006;21:3164-71.

37. Johnell K, Klarin I. The relationship between number of drugs and potential drug-drug interactions in the elderly. Drug Saf. 2007;30:911-8.

38. Boeker EB, Ram K, Klopotowska JE, et al. An individual patient data meta-analysis on factors associated with adverse drug events in surgical and non-surgical inpatients. $\mathrm{Br} \mathrm{J}$ Clin Pharmacol. 2015;79:548-57.

39. Alassaad A, Bertilsson M, Gillespie U, et al. The effects of pharmacist intervention on emergency department visits in patients 80 years and older: subgroup analyses by number of prescribed drugs and appropriate prescribing. PLoS One. 2014;9:e111797. 